\title{
Biomarkers of Oxidative Stress in Vascular Dementia Patients
}

\author{
Guang-Xia Shi, Cun-Zhi Liu, Lin-Peng Wang, Li-Ping Guan, Si-Qian Li
}

\begin{abstract}
Objective: Little is known about the role of oxidative stress in the pathogenesis of vascular dementia (VaD). The aim of this study was to investigate the biomarkers of oxidative stress in urine, as reflected by 8-hydroxydeoxyguanosine (8-OHdG), 8-isoprostaglandin $\mathrm{F}_{2 \mathrm{a}}\left(8\right.$-isoPGF $\mathrm{Pa}_{2 \mathrm{a}}$ ) and nitrotyrosine (NT) levels, in a group of well characterized VaD patients and in two control groups of Vascular Not Demented (VaND) patients and healthy subjects. Methods: Ninety-six subjects from the Tianjin municipality in China were recruited. Forty-six patients were in the VaD group, 24 patients with VaND and 26 persons with no signs of cognitive disorder were employed as control groups. Urinary 8-OHdG and 8-isoPGF ${ }_{2 \mathrm{a}}$ was performed using enzyme-linked immunosorbent assay (ELISA), and urinary NT levels were measured by chemiluminescence detection. Results: Significantly higher urinary 8-OHdG levels were detected in $\mathrm{VaD}$ patients compared to VaND patients and healthy control subjects. In contrast, urinary 8-isoPGF la $_{\mathrm{a}}$ levels were significantly lower in VaD patients compared with two control groups. For NT levels, no statistically significant differences were observed among the three groups. Conclusion: Increased urinary $8-\mathrm{OHdG}$ level was a potential marker of oxidative stress in VaD patients. Furthermore, it is also important to take into account potential confounders in order to improve the identification of changes in the status of oxidative stress as related to $\mathrm{VaD}$.
\end{abstract}

RÉSUMÉ: Biomarqueurs du stress oxydatif chez les patients atteints de démence vasculaire. Objectif : Il existe peu d'information sur le rôle que joue le stress oxydatif dans la pathogenèse de la démence vasculaire (DVa). Le but de cette étude était d'examiner les biomarqueurs du stress oxydatif dans l'urine par la détermination des taux de 8-hydroxydéoxyguanosine (8-OHdG), de 8-iso prostaglandine F2a (8-isoPGF2a) et de nitrotyrosine (NT) chez un groupe de patients bien caractérisés atteints de DVa et chez deux groupes témoins, soit un groupe de patients avec atteinte vasculaire sans démence (VaSD) et un groupe de sujets sains. Méthode : Quatre-vingt-seize sujets de la municipalité de Tianjin en Chine ont été recrutés. Le groupe DVa était constitué de quarante-six patients, le groupe VaSD de 14 patients et le groupe témoin sain de 26 sujets. Le taux urinaire de 8-OHdG et de 8isoPGF2a a été déterminé par un dosage immuno-enzymatique ELISA et le taux urinaire de NT par chimioluminescence. Résultats : Un taux significativement plus élevé de 8-OHdG urinaire a été détecté chez les patients atteints de DVa par rapport aux patients atteints de VaSD et aux sujets témoins sains. Par contre, le taux urinaire de 8-isoPGF2a était significativement plus bas chez les patients atteints de DVa par rapport aux deux groupes témoins. Aucune différence significative n'a été observée entre les trois groupes quant au taux de NT. Conclusion : Un taux augmenté de 8-OHdG urinaire pourrait constituer un marqueur du stress oxydatif chez les patients atteints de DVa. De plus il est important de tenir compte de facteurs confondants possibles afin d'améliorer l'identification des changements dans le niveau du stress oxydatif en relation à la DVa.

Can. J. Neurol. Sci. 2012; 39: 65-68

Vascular dementia (VaD) is a general term for dementia caused by organic lesions of vascular origin, which is the result of brain injury produced by cerebrovascular disease, either hemorrhagic or ischemic, or by hypoperfusive lesions resulting from cardiac disease or circulatory failure. It remains the second most common cause of dementia after Alzheimer's disease (AD), accounting for $10-50 \%$ of all cases of dementia ${ }^{1,2}$. However, the high prevalence of cerebrovascular and cardiovascular pathologies capable of producing $\mathrm{VaD}$ make it the most common form of dementia in the elderly ${ }^{3}$. It is reported the annual medical costs for $\mathrm{VaD}$ patients were substantially higher than costs for AD patients ${ }^{4}$.

Oxidative stress may be defined as an imbalance between free radicals, such as reactive oxygen species (ROS) and reactive nitrogen species (RNS) acting as oxidants, and levels of protecting antioxidant defence systems in favor of the former. The excessive production of free radicals could be harmful as they damage cellular lipids, sugars, proteins and nucleic acids, inhibiting their normal function and leading to cell death ${ }^{5}$. The brain is more susceptible to oxidative damage than any other organ due to its high oxygen consumption and it is relatively rich in polyunsaturated fatty acids which are easily oxidized. Extensive evidence supports a role for free radical generation and oxidative injury in the pathogenesis of stroke and other vascular disease ${ }^{6,7}$.

Free radicals are short-lived and are difficult to measure in biological samples. However, there are some indirect indexes that can be used to examine sequela of free radical production. Urinary 8-hydroxydeoxyguanosine (8-OHdG) level has been validated as a biomarker of the rate of oxidative DNA modification $^{8}$. The formation of $8-\mathrm{OHdG}$ in DNA is an

From the Acupuncture and Moxibustion Department (GXS, CZL, LPW), Beijing Hospital of Traditional Chinese Medicine affiliated to Capital Medical University, Beijing, China; Acupuncture and Moxibustion department (LPG, SQL), The First Hospital affiliated to Tianjin University of Traditional Chinese Medicine, Tianjin, China."

Received February 22, 2011. Final Revisions Submitted July 20, 2011. Correspondence to: Cun-Zhi Liu, Acupuncture and Moxibustion Department, Beijing Hospital of Traditional Chinese Medicine affiliated to Capital Medical University, 23 Meishuguanhou Street, Dongcheng District, Beijing, 100010, China. Tel: 00861052176905; Fax:00861052176813; E-mail: lcz623780@126.com" 
important mechanism of oxygen-radical induced mutagenesis and it is water-soluble and readily excreted in urine without further metabolism. 8-iso-prostaglandin F2a (8-isoPGF ${ }_{2 \mathrm{a}}$ ), which is produced from oxidative modification of polyunsaturated fatty acids via a free radical-catalyzed mechanism, has been suggested as a potentially useful biomarker for lipid peroxidation ${ }^{9}$. Furthermore, nitrotyrosine (NT) is believed to be involved in free radical chemistry reactions and appears to be an available biomarker for protein oxidation ${ }^{10}$.

Although oxidative stress plays a role in the brain damage seen in $\mathrm{VaD}$, there is a lack of studies assessing the presence and levels of biomarkers of oxidative damage in $\mathrm{VaD}$ patients. Therefore, we investigated the biomarkers of oxidative stress in urine, as reflected by $8-\mathrm{OHdG}, 8-$ isoPGF $_{2 \mathrm{a}}$ and $\mathrm{NT}$, in a group of well characterized $\mathrm{VaD}$ patients and in two control groups of Vascular Not Demented (VaND) patients and healthy subjects.

\section{Materials and methods}

\section{Subjects}

Between June 2008 and July 2009, a total of 96 subjects from the Tianjin municipality in China were recruited. The VaD group was comprised of 46 patients with ages ranging from 50 to 80 years. Patients met criteria for $\mathrm{VaD}$ according to the American Psychiatric Association (1994) (DMS-IV) and the National Institute of Neurological Disorders and Stroke-Association Internationale pour la Recherche et 1 Enseignement en Neurosciences (NINDS-AIREN), confirmed by neuropsychological examination, verified by neuroimaging (magnetic resonance imaging (MRI) and/or computed tomography (CT)). Patients had Mini-Mental State Examination (MMSE) scores of between 10 and 26 inclusive, indicating presence of dementia. All patients were free of any significant mental illnesses, and Hachinski Ischemia Scale scores were $\geq 7$. They were included at more than two weeks after onset of VaD.
Twenty-four patients (age from 50 to 80 years) with VaND during the chronic phase were employed as controls. Cerebrovascular lesions were confirmed by neuroimaging (MRI and/or CT). The time after onset of VaND at entry to the present study ranged from three to nine months, and the MMSE scores were greater than 26.

Twenty-six persons with no signs of cognitive dysfunction were assigned to the age-matched healthy control group. They comprised individuals who visited the hospital for their annual physical check-up, had no history of circulatory disorders and showed no evident abnormalities in their electrocardiography, chest X-rays, urinalysis or blood chemistry. The MMSE scores were greater than 26. Patients receiving antioxidant vitamin therapy were excluded.

The protocol of this study was approved by the local ethics review boards, and conducted according to common standard guidelines (Declaration of Helsinki, Good Epidemiological Practice: http:// www.dundee.ac.uk/iea/GoodPract.htm).

\subsection{Urine collection and assays}

Urine samples were stored at $-80^{\circ} \mathrm{C}$ immediately after collection until analysis. The urinary levels of 8-OHdG and 8isoPGF $_{2 \mathrm{a}}$ were measured by enzyme-linked immunosorbent assays (ELISA), using 8-OHdG enzyme immunoassay kit (Cayman Chemical Company, Ann Arbor, MI, USA) and 8isoPGF $_{2 \mathrm{a}}$ enzyme immunoassay kit (8-isoPGF ${ }_{2 \mathrm{a}}$ Assay Kit; Assay Designs Inc., Ann Arbor, MI, USA) respectively. Urinary NT level was measured using a chemiluminescence detection method with a nitrotyrosine assay kit (Millipore Corp., Bedford, MA, USA). Creatinine levels were analyzed to determine if differences in the biochemical parameters observed among the three groups could be attributed to group differences in the concentration of creatinine in urine.

Table 1: Demographic and clinical characteristics of VaD patients and controls

\begin{tabular}{|c|c|c|c|c|}
\hline & $\mathrm{VaD}$ & VaND & Healthy control & $P$ \\
\hline Number & 46 & 24 & 26 & \\
\hline Age (mean $\pm \mathrm{SD})$ (years) & $63.8 \pm 11.2$ & $61.5 \pm 7.1$ & $58.1 \pm 7.2$ & 0.05 \\
\hline $\mathrm{M} / \mathrm{F}$ & $28 / 18$ & $18 / 6$ & $19 / 5$ & 1.00 \\
\hline $\operatorname{MMSE}(\operatorname{mean} \pm \mathrm{SD})$ & $17.7 \pm 3.6$ & $28.8 \pm 1.2$ & $29.9 \pm 0.3$ & 0.00 \\
\hline \multicolumn{5}{|l|}{$\mathrm{MRI} / \mathrm{CT}$ scan } \\
\hline Cystic infarcts (n/\%) & $11 / 23.9 \%$ & $6 / 25.0 \%$ & & 0.57 \\
\hline Lacunar infarctions(n/\%) & $33 / 71.7 \%$ & $17 / 70.8 \%$ & & 0.57 \\
\hline Hemorrhage(n/\%) & $2 / 4.4 \%$ & $1 / 4.17 \%$ & & 0.73 \\
\hline \multicolumn{5}{|l|}{ Lesion site } \\
\hline Cortical(n/\%) & $5 / 10.9 \%$ & $3 / 12.5 \%$ & & 0.56 \\
\hline Basal ganglion(n/\%) & $25 / 54.4 \%$ & $14 / 58.3 \%$ & & 0.48 \\
\hline Cerebellar(n/\%) & $2 / 4.4 \%$ & $0 / 0$ & & 0.43 \\
\hline Brian sterm(n/\%) & $5 / 10.9 \%$ & $1 / 4.2 \%$ & & 0.32 \\
\hline Muliple(n/\%) & $6 / 13.0 \%$ & $1 / 4.2 \%$ & & 0.23 \\
\hline Coronary artery disease $(\mathrm{n} / \%)$ & $17 / 37.0 \%$ & $7 / 29.2 \%$ & $2 / 7.7 \%$ & 0.03 \\
\hline Hypertension (n/\%) & $36 / 78.3 \%$ & $17 / 70.8 \%$ & $10 / 38.5 \%$ & 0.00 \\
\hline Diabetes mellitus (n/\%) & $6 / 13.0 \%$ & $6 / 25.0 \%$ & $3 / 11.5 \%$ & 0.34 \\
\hline
\end{tabular}




\section{Statistical analysis}

All statistical analysis was performed using SPSS statistical software package version 10.0 (SPSS Inc., Chicago, Illinois, USA). After testing for normal distribution, analysis of variance (ANOVA) or Kruskal-Wallis test, was used. Additional analysis of the data was performed using correlation analysis. The data were expressed as mean \pm standard deviation $(\mathrm{SD})$. All $\mathrm{P}$ values under 0.05 were considered significant.

\section{Results}

The characteristics of $\mathrm{VaD}$ and $\mathrm{VaND}$ patients and healthy control subjects are detailed in Table 1. The MMSE scores in $\mathrm{VaD}$ patients were significantly lower than in the other two groups. Moreover, no significant differences exsited between VaND patients and healthy control subjects. The VaD and VaND patients had significantly higher incidence of coronary artery disease and hypertension in comparison to healthy control subjects. A statistically significant inverse correlation was observed in $\mathrm{VaD}$ patients between MMSE and the urinary 8OHdG (Rs=0.070, p=0.017). A statistically significant correlation was observed in $\mathrm{VaD}$ patients between MMSE and urinary 8-isoPGF ${ }_{2 \mathrm{a}}$ and NT levels ( $\mathrm{Rs}=0.118, \mathrm{p}=0.001$ for 8isoPGF $_{2 \mathrm{a}}$ and $\mathrm{Rs}=0.237, \mathrm{p}=0.000$ for NT).

Urinary 8-OHdG levels were significantly higher $(\mathrm{p}<0.05)$ in $\mathrm{VaD}$ patients compared with the other two groups. However, VaND patients showed no significant differences in comparison with healthy control subjects (Table 2).

The urinary 8-isoPGF ${ }_{2 a}$ level was significantly lower in $\mathrm{VaD}$ patients compared to VaND patients and healthy control subjects. Whereas, no significant differences were found between VaND patients and healthy control subjects (Table 2).

For the NT levels, no statistically significant differences were detected among VaD patients, VaND and healthy control subjects (Table 2).

\section{DisCUSSIONS}

The high prevalence of $\mathrm{VaD}$ in aging populations emerges as a major public health problem. There is a need for prospective studies to clarify the pathogenesis of this condition and to provide appropriate measures for prevention and treatment of
$\mathrm{VaD}$. A lot of studies demonstrate that $\mathrm{VaD}$ and sroke share some common pathogenetic mechanisms including the role of oxidant stress $^{11}$. Ryglewicz et al showed that in patients with $\mathrm{VaD}$ as compared with AD and healthy controls, antioxidant defense decreased and the susceptibility to oxidative stress increased ${ }^{12}$.

ROS-induced oxidative DNA damage is believed to contribute to neuronal cell death and neurological dysfunction. Urinary $8-\mathrm{OHdG}$ level could represent the average rate of oxidative DNA damage in the whole body. It could serve as marker of oxidative stress because of its noninvasive. Plasma 8OHdG level increased after ischemic stroke, with a significant association with brain oxidation ${ }^{13}$. In the present study, urinary 8-OHdG level significantly increased in VaD patients compared to VaND and healthy controls. This was consistent with other studies suggesting that dementia patients were under increased oxidative stress ${ }^{14}$. Plenty of evidence suggests that oxidation of DNA is affected by aging and cigarette smoking ${ }^{15,16}$. In contrast, other studies indicated that neither the age nor the smoking status appear to have impact on the value of normal reference range of urinary $8-\mathrm{OHdG}^{17,18}$.

Lipid peroxidation, which refers to the oxidative degradation of lipids, is one of the major outcomes of free radical-mediated injury. Increased urinary 8 -isoPGF ${ }_{2 a}$ level was reported in dementia patients compared with controls ${ }^{19}$, while others demonstrated that there was no difference between dementia patients and healthy controls ${ }^{20,21}$. Inconsistent with the results mentioned above, our study showed a significantly decrease in the level of urinary 8 -isoPGF $2 \mathrm{a}$ in $\mathrm{VaD}$ patients compared to healthy subjects. Methodological differences and the autooxidation of samples in the process of preparation could explain these conflicting results. Furthermore, multiple physiological and pathological processes influence the concentration of isoprostanes in urine (e.g. lifestyle, diet, physical activity, smoker or non-smoker, cardiovascular diseases, diabetes). There was evidence indicating that 8 -isoPGF ${ }_{2 \mathrm{a}}$ level in the body was closely linked to cigarette smoking and hypercholesterolemia ${ }^{22}$. However, subjects with cigarette smoking history were not excluded in our study. Accordingly, the urinary 8-isoPGF $2 \mathrm{a}$ levels might not accurately reflect lipid peroxidation and it was necessary to control for confounding results when analysing.

Table 2: Comparison of urinary 8-OHdG, 8-isoPGF2a and NT levels in the three groups

\begin{tabular}{cccc}
\hline Groups & $\begin{array}{c}8-\mathrm{OHdG} \\
\text { (ng/mg creatinine) }\end{array}$ & $\begin{array}{c}8 \text {-isoPGF } 2 \mathrm{a} \\
(\mathrm{ng} / \mathrm{mg} \text { creatinine) }\end{array}$ & $\begin{array}{c}\text { NT } \\
\text { (ng/mg creatinine) }\end{array}$ \\
\hline $\mathrm{VaD}$ & $13.31 \pm 7.53^{*}$ & $24.52 \pm 5.62^{*}$ & $30.92 \pm 11.93$ \\
VaND & $10.20 \pm 5.46$ & $28.68 \pm 6.14$ & $26.73 \pm 6.75$ \\
Healthy control & $10.23 \pm 3.55$ & $31.89 \pm 9.24$ & $32.94 \pm 11.56$ \\
\hline
\end{tabular}

* Significant difference compared to VaND $(\mathrm{p}<0.05)$. Significant difference compared to healthy control $(\mathrm{p}<0.05)$. Significantly higher urinary 8 -OHdG level was detected in $\mathrm{VaD}$ patients compared to VaND patients and healthy control subjects. Urinary 8-isoPGF ${ }_{2 \mathrm{a}}$ level was significantly lower in $\mathrm{VaD}$ patients compared with VaND patients and healthy control. No statistically significant differences were observed among patients in the three groups in NT levels. 
Nitric oxide (NO) may react with superoxide radical anions giving peroxynitrite (ONOO-). Peroxynitrite acts on the protein molecule in the tyrosine residue, and its product NT could reduce the activity of enzymes in vivo, and prevent the activation of protein kinases. Previous studies suggested that the formation of NT was associated with a high degree of brain injury ${ }^{23,24}$. However, one study did not find any difference in protein carbonyls between a small sample of stroke patients and controls ${ }^{25}$. Similarly to this study, we have found no difference in urinary NT among the three groups. Cigarette smoking has been shown to accelerate the nitrotyrosine-mediated oxidation ${ }^{26,27}$. Therefore, the value of these biomarkers when studying dementia is strictly linked to the possibility of taking into account potential confounders (e.g. diet, smoking, comorbidity). One of the limitations of our study is that we did not exclude the subjects with cigarette smoking. In addition, the sample size in the present study was relatively small.

In conclusion, urinary 8-OHdG level was significantly higher while 8-isoPGF $2 \mathrm{a}$ level was lower in $\mathrm{VaD}$ patients in comparison to VaND patients and healthy controls. No statistically significant differences were detected in urinary NT levels among the three groups. This suggests that, even if the role of biochemical-markers in $\mathrm{VaD}$ has not yet been well-defined, urinary 8-OHdG levels are a potential marker of oxidative stress in $\mathrm{VaD}$ patients. A further step understanding urinary biomarkers in $\mathrm{VaD}$ patients compared to $\mathrm{AD}$ patients should be made in the future. Moreover, it is important to consider more than one biomarker in order to improve the identification of changes in the status of oxidative stress. The balance between antioxidants and by-products of oxidative stress in the body might be the best approach for the evaluation of oxidative stress in dementia patients ${ }^{28}$. Further studies are needed.

\section{ACKNOWLEDGements}

The study was funded by the National Natural Science Foundation of China (No. 30801483), and China Postdoctoral Science Foundation funded project (200801054).

\section{REFERENCES}

1. Dubois MF, Hébert R. The incidence of vascular dementia in Canada: a comparison with Europe and East Asia. Neuroepidemiology. 2001; 20(3):179-87.

2. Plassman BL, Langa KM, Fisher GG, et al. Prevalence of dementia in the United States: the aging, demographics, and memory study. Neuroepidemiology. 2007; 29(1-2):125-32.

3. Román GC. Vascular dementia may be the most common form of dementia in the elderly. J Neurol Sci. 2002; 15(7-10):203-4.

4. Fillit H, Hill J. The costs of vascular dementia: a comparison with Alzheimer's disease. J Neurol Sci. 2002; 203-204:35-9.

5. Serra JA, Domínguez RO, de Lustig ES, et al. Parkinson's disease is associated with oxidative stress: comparison of peripheral antioxidant profiles in living Parkinson's, Alzheimer's and vascular dementia patients. J Neural Transm. 2001; 108(10): $1135-48$.

6. Drummond GR, Selemidis S, Griendling KK, Sobey CG. Combating oxidative stress in vascular disease: NADPH oxidases as therapeutic targets. Nat Rev Drug Discov. 2011; 10 (6): $453-71$.

7. Polidori MC, Mecocci P, Frei BF. Plasma Vitamin C levels are decreased and correlated with brain damage in patients with intracranial hemorrhage or head trauma. Stroke. 2001; 32: $898-902$.
8. Gustaw-Rothenberg K, Lerner A, Bonda DJ, et al. Biomarkers in Alzheimer's disease: past, present and future. Biomark Med. 2010; 4(1):15-26.

9. Kadiiska MB, Gladen BC, Baird DD, et al. Biomarkers of oxidative stress study II: are oxidation products of lipids, proteins, and DNA markers of CCl4 poisoning? Free Radic Biol Med. 2005; 38(6):698-710.

10. Ter Steege JC, Koster-Kamphuis L, van Straaten EA, Forget PP, Buurman WA. Nitrotyrosine in plasma of celiac disease patients as detected by a new sandwich ELISA. Free Radic Biol Med. 1998; 25(8):953-63.

11. Manolescu BN, Berteanu M, Oprea E, et al. Dynamic of oxidative and nitrosative stress markers during the convalescent period of stroke patients undergoing rehabilitation. Ann Clin Biochem. 2011.

12. Ryglewicz D, Rodo M, Kunicki PK, et al. Plasma antioxidant activity and vascular dementia. J Neurol Sci. 2002; 203-204: 195-7.

13. Rao KS. Free radical induced oxidative damage to DNA: relation to brain aging and neurological disorders. Indian $\mathrm{J}$ Biochem Biophys. 2009; 46(1):9-15.

14. Behl C. Alzheimer's disease and oxidative stress: implications for novel therapeutic approaches. Prog Neurobiol. 1999; 57(3): 301-23.

15. Pilger A, Germadnik D, Riedel K, Meger-Kossien I, Scherer G, Rüdiger HW. Longitudinal study of urinary 8-hydroxy-2'deoxyguanosine excretion in healthy adults. Free Radic Res. 2001; 35(3):273-80.

16. Pourcelot S, Faure H, Firoozi F, et al. Urinary 8-oxo-7, 8-dihydro2'-deoxyguanosine and 5-(hydroxymethyl) uracil in smokers. Free Radic Res. 1999; 30(3):173-80.

17. Musarrat J, Arezina-Wilson J, Wani AA. Prognostic and aetiological relevance of 8-hydroxyguanosine in human breast carcinogenesis. Eur J Cancer. 1996; 32A(7):1209-14.

18. Wu LL, Chiou CC, Chang PY, Wu JT. Urinary 8-OHdG: a marker of oxidative stress to DNA and a risk factor for cancer, atherosclerosis and diabetics. Clin Chim Acta. 2004; 339(1-2): $1-9$.

19. Praticò D, Clark CM, Lee VM, Trojanowski JQ, Rokach J, FitzGerald GA. Increased 8, 12-iso-iPF2alpha-VI in Alzheimer's disease: correlation of a noninvasive index of lipid peroxidation with disease severity. Ann Neurol. 2000; 48(5):809-12.

20. Praticò D, MY Lee V, Trojanowski JQ, Rokach J, Fitzgerald GA. Increased F2-isoprostanes in Alzheimer's disease: evidence for enhanced lipid peroxidation in vivo. FASEB J. 1998; 12(15): 1777-83.

21. Kim KM, Jung BH, Paeng KJ, Kim I, Chung BC. Increased urinary $\mathrm{F}$ (2)-isoprostanes levels in the patients with Alzheimer's disease. Brain Res Bull. 2004; 64(1):47-51

22. Lee SH, Kim I, Chung BC. Increased urinary level of oxidized nucleosides in patients with mild-to-moderate Alzheimer's disease. Clin Biochem. 2007; 40(13-14):936-8.

23. Cakatay U, Telci A, Kayalì R, Tekeli F, Akçay T, Sivas A. Relation of oxidative protein damage and nitrotyrosine levels in the aging rat brain. Exp Gerontol. 2001; 36(2):221-9.

24. Doğru-Abbasoğlu S, Parildar-Karpuzoğlu H, Balkan J, AykaçToker G, Uysal M. Nitrotyrosine formation and heme oxygenase-1 expression in endotoxemic cirrhotic rats. Arch Med Res. 2007; 38(1):28-33.

25. Mariani E, Polidori MC, Cherubini A, Mecocci P. Oxidative stress in brain aging, neurodegenerative and vascular diseases: an overview. J Chromatogr B Analyt Technol Biomed Life Sci. 2005; 827(1):65-75.

26. Yamaguchi Y, Kagota S, Haginaka J, Kunitomo M. Participation of peroxynitrite in oxidative modification of LDL by aqueous extracts of cigarette smoke. FEBS Lett. 2002; 512(1-3):218-22.

27. Pignatelli B, Li CQ, Boffetta P, et al. Nitrated and oxidized plasma proteins in smokers and lung cancer patients. Cancer Res. 2001; 61(2):778-84.

28. Cherubini A, Ruggiero C, Polidori MC, Mecocci P. Potential markers of oxidative stress in stroke. Free Radic Biol Med. 2005; 39(7):841-52. 